\title{
Optimal injection interval for testosterone undecanoate treatment of hypogonadal and transgender men
}

\author{
Nandini Shankara Narayana D, Lam P Ly, Veena Jayadev, Carolyn Fennell, Sasha Savkovic, Ann J Conway and \\ David J Handelsman
}

Andrology Department, Concord Hospital and ANZAC Research Institute, University of Sydney, Sydney, Australia

Correspondence should be addressed to D J Handelsman: djh@anzac.edu.au

\begin{abstract}
Objective: To define the optimized inter-injection interval of injectable testosterone undecanoate (TU) treatment for hypogonadal and transmen based on individual dose titration in routine clinical practice.

Design and methods: A prolective observational study of consecutive TU injections in men undergoing testosterone replacement therapy for pathological hypogonadism or masculinization of female-to-male transgender (transmen) subject to individual dosing titration to achieve a stable replacement regimen.

Results: From 2006 to 2019, 6899 injections were given to 325 consecutive patients. After excluding the 6-week loading dose, 6300 injections were given to 297 patients who had at least three and a median of 14 injections. The optimal injection interval (mean of last three injection intervals) had a median of 12.0 weeks (interquartile range 10.4-12.7 weeks). The interval was significantly influenced by age and body size (body surface area, BSA) but not by diagnosis or trough serum LH, FSH, and SHBG. Longer ( $\geq 14$ weeks; 68/297, 23\%), but not shorter ( $\leq 10$ weeks; 22/297, 7.4\%), intervals were weakly correlated with age but not diagnosis or other covariables. Low blood hemoglobin increased with trough serum testosterone to reach plateau once testosterone was about $10 \mathrm{nmol} / \mathrm{L}$ or higher.

Conclusion: Optimal intervals between TU injection after individual titration resulted in the approved 12 -week interval in $70 \%$ of patients with only minor influence for clinical application of BSA and not of trough serum LH, FSH, and SHBG. Individually optimized inter-injection interval did not differ between men with primary or secondary hypogonadism or transmen.
\end{abstract}

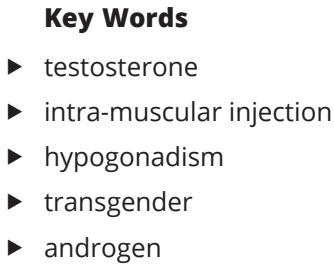

Endocrine Connections (2021) 10, 758-766

\section{Introduction}

Since the discovery and first clinical use of testosterone in the 1930s, its minimal oral bioavailability has led to administration via every non-oral route to circumvent rapid gut and liver metabolism (1). Since the 1950s, the most common route of administration has been the parenteral injection of testosterone as a pro-drug esterified to short-chain aliphatic fatty acids in a vegetable oil vehicle (2). These injectable products are affordable with depot effects that facilitate treatment adherence by requiring fewer injections over time. Testosterone is liberated from the injected pro-drug esters by non-specific esterase when they enter the bloodstream. The duration of action of depot injectable testosterone esters depends on the hydrophobicity of the aliphatic side-chain retarding https://ec.bioscientifica.com

https://doi.org/10.1530/EC-21-0109 (c) 2021 The authors Published by Bioscientifica Ltd

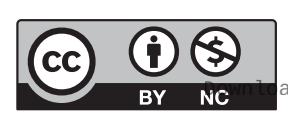

This work is licensed under a Creative Commons Attribution-NonCommercial 4.0 International License. ded from Bioscientifica.com at $04 / 26 / 2023$ 07:02:24AM 
ester release from the oil depot, side-chain steric hindrance slowing esterase action as well as the lymphatic absorption of oil vehicle into the circulation (3). Accordingly, injectable testosterone ester products have a duration of action ranging from short-acting (propionate) requiring one or two injections per week, medium acting (enanthate, cypionate, mixed esters) requiring injections every 2 weeks and a long-acting depot testosterone undecanoate (TU) typically administered at 12-week intervals (1). Oral TU has been available since the 1970s in an oil-filled capsule marketed worldwide and recently in the US (4). Injectable TU was developed in 1980s China (5) before worldwide and US marketing. Injectable testosterone TU is now, together with transdermal testosterone products, the most widely prescribed modalities of testosterone replacement therapy (6) as well as for masculinizing transmen (7).

As testosterone replacement therapy for irreversible pathological hypogonadism needs to be life-long, the convenience of a regimen facilitates long-term compliance with therapeutic dosing. All testosterone products require individual optimizing of the patient's regimen to ensure the best efficacy and safety outcomes. Dose titration is simpler for short-acting products which have a rapid onset and offset of testosterone absorption and action. However, dose titration for long-acting depots is more challenging and time-consuming $(8,9)$. The safety and efficacy profile of injectable TU under clinical trial conditions is well established $(10,11,12)$, and it generally has a good safety profile in routine clinical practice. There are few side-effects other than transient injection site pain (13) and pulmonary oil microembolization (POME, prevalence of $2.0 \%$ ) whereas injection site hematoma is rare even among men using antiplatelet or anticoagulants (14). Clinical studies of testosterone products originate primarily from clinical trials designed with standardized treatment regimens to meet regulatory requirements for marketing. Yet, the post-marketing clinical efficacy profile in routine medical practice may differ from the registration clinical development program. Outside of standardized randomized clinical trials, larger clinical studies of injectable TU in regular practice also mostly use a fixed standard injection interval in which a few report variability in inter-injection interval without defining the factors determining shorter or longer inter-injection intervals. Injectable $\mathrm{TU}$ has also become to be increasingly used to masculinize female-to-male transgenders (F2M, transmen) $(7,15)$ with treatment following standard dosing regimen recommendations. We, therefore, undertook a prospective surveillance study of TU injections in the routine clinical practice of an experienced single academic center so that optimized regimens by individual dose titration could be used to evaluate the duration of action and its clinically significant determinants and to determine the duration of action in transmen compared with hypogonadal men (16).

\section{Materials and methods}

\section{Participants and injections}

This prolective study (17) summarized prospectively collected data from consecutive patients attending the Andrology Department of Concord Hospital between 2006 and 2019 to receive regular TU injections as testosterone replacement therapy for pathological disorders of the hypothalamic, pituitary, or testis (excluding 'Andropause', 'LowT', 'late-onset or functional hypogonadism') or were female-to-male transgender (transmen, F2M) patients. A waiver of ethics approval was provided by the Sydney Local Health District Human Ethics Committee for summarizing completed treatment data of patients. Men were divided into primary (hypergonadotrophic), secondary (hypogonadotrophic) hypogonadism or transmen groups with the causes of hypogonadism described previously (14). Injections were administered by experienced nurses delivering $1000 \mathrm{mg}$ of TU in $4 \mathrm{~mL}$ of castor oil vehicle using a 21-gauge needle. Injections were placed deeply into the upper outer gluteal muscle (on alternating sides) slowly after aspiration to exclude venous injection.

Treatment was initiated with a first dose $(1000 \mathrm{mg})$ followed by a loading dose $(1000 \mathrm{mg})$ at 6 weeks and then regular injections at initially 12 -week intervals according to the approved product information (Reandron, Bayer). Blood was sampled for monitoring trough serum testosterone (blood sampled immediately prior to the next injection) together with serum LH, FSH, and SHBG in the same sample. Individual dose titration was performed by evaluating at each visit whether the treatment had maintained symptomatic benefit according to the patients leading symptom $(18,19)$ coupled with trough blood testosterone concentration together with serum LH and FSH suppression (in primary hypogonadism) to form a composite judgment whether efficacy was adequately maintained at 12 week inter-injection interval. In most patients, the 12-week intervals did not require adjustment. When there was consistent evidence of symptomatic run out (recurrence of lead symptoms) before the end of the treatment period coupled with a low trough serum testosterone and (in primary hypogonadism) inadequate suppression of serum LH and FSH, the inter-injection 
interval would be reduced by 1- or 2-week intervals and then iteratively re-evaluated. Conversely, where there were unacceptable overdosage side-effects (erythrocytosis, unacceptable mood, or behavioral changes) with elevated trough serum testosterone, the inter-injection interval was increased by 1 or 2 weeks at a time. Data from seven patients (six F2M, one hypogonadal) for whom the TU dose was reduced to less than $1000 \mathrm{mg}$ were excluded from the analysis. Unlike the trough serum hormone concentrations measured at the time of each injection (four times per year) as a measure of efficacy, blood hemoglobin and serum PSA were measured much less frequently about once per year, and for men, over the age of 50 years, respectively. Optimal inter-injection interval was defined as the mean of the last three injections. A short interval was defined as an average of $<10$ weeks between injections and a long interval as an average of $>14$ weeks.

\section{Assays}

Serum testosterone, LH, FSH, and SHBG were measured by automated Roche immunoassays in the Diagnostic Pathology Unit, Concord Hospital subject to participation in regular external quality control. The between-assay CVs using multi-level QC samples per analyte were 1.4-3.0\% measured over at least 130 consecutive assays for all four analytes. Hemoglobin and prostate-specific antigen (PSA) were measured by routine autoanalyzer method in the Concord Hospital Diagnostic Pathology Unit and subject to regular external quality control.

\section{Data analysis}

Data were analyzed by appropriate methods for continuous data using NCSS 2021 (descriptive data, ANOVA and covariance, linear regression, linear mixed models for repeated measures) and for categorical data using StatXact version 9 software as required. The linear mixed model for repeated measures investigated the length of an interinjection interval with a main between effect of diagnosis, and potential covariates comprising age, measures of body size or physique, serum hormones, and a subject term as a random variable using restricted maximum likelihood with a one-term autoregressive covariance structure. The relative explanatory power of different models was evaluated by the entropy reduction metric, the Akaike Information Criterion (AIC), according to which model had the lowest AIC value (i.e. greatest explanatory power). BMI was defined as weight (kilograms)/height $(\text { meter })^{2}$, and body surface area (BSA) was calculated by the
Gehan-George formula (20). Data distribution was assessed by Box-Cox analysis with optimal normalizing power transformation if required, performed according to the $\lambda$ criterion (21). Regression modeling using non-linear curve fitting assessed a wide variety of models for the goodness of fit to the data according to the highest R squared statistic.

\section{Results}

The study data covered 6899 injections of $1000 \mathrm{mg}$ TU administered to 326 patients (14). After excluding the 6-week loading doses, the analysis involved 6300 TU injections administered to 297 patients who had at least three serial injections (Table 1). Study participants had a median of 14 injections (interquartile range 7-25 injections).

Preliminary analysis showed that age and all measures of body size or physique were significant predictors of optimized injection interval. These anthropometric variables comprised height, weight, BMI (a measure of weight for height or obesity), and body surface area (a measure of overall body size based on the product of weight and height). However, as these metrics would be highly collinear, they could not be used in the same models concurrently so we conducted a preliminary analysis to deduce the most predictive body size variable. When evaluated according to minimizing model-derived AIC for the analysis of inter-injection interval, BSA (AIC 20,398) produced the greatest reduction to model entropy followed by height $(20,433)$, weight $(20,560)$ and BMI $(20,704)$. Hence for further modeling, BSA was used exclusively as a measure of body size and dose expressed per $\mathrm{m}^{2}$.

The median (and modal) inter-injection interval was 12.0 weeks (interquartile range 10.4-12.7 weeks, range 7-16 weeks) and did not differ between men with either primary or secondary hypogonadism or transmen (Fig. 1 and Table 1). An inter-injection interval of between 10 and 14 weeks was the optimized interval for $70 \%$ of patients. Regression analysis of optimal inter-injection intervals (Fig. 2 and Table 2) indicated significant initial univariate effects of age (standardized regression coefficient -0.223 , $P<0.001$ ) and BSA (standardized regression coefficient $0.244, P<0.001)$ but without any significant effect of age $\times$ BSA interaction $(P=0.26)$ nor of diagnosis $(P=0.74)$. From the linear mixed model analysis including all data, the inter-injection interval was significantly correlated with positive effects of age $(P=0.004)$ and negative effects of BSA $(P=0.002)$ but, after adjustment for those covariables, neither diagnosis nor serum LH, FSH, SHBG

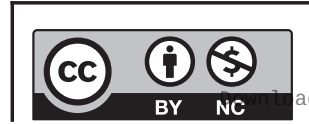

This work is licensed under a Creative Commons Attribution-NonCommercial 4.0 International License. ded from Bioscientifica.com at 04/26/2023 07:02:24AM 
Table 1 Results of individual dose titration.

\begin{tabular}{l}
\hline Variable \\
\hline Patients $(n)$ \\
Age (years) \\
Height $(\mathrm{cm})$ \\
Weight $(\mathrm{kg})$ \\
BMI $\left(\mathrm{kg} / \mathrm{m}^{2}\right)$ \\
BSA $\left(\mathrm{m}^{2}\right)$ \\
Pre-titration \\
Serum LH (IU/L) \\
Serum FSH (IU/L) \\
Serum SHBG (nmol/L) \\
Post-titration \\
Optimal interval (weeks) \\
Injections/patient $(n)$ \\
Dose per m ${ }^{2}$ \\
Serum LH (IU/L) \\
Serum FSH (IU/L) \\
Serum SHBG (nM) \\
Serum testosterone (nM)
\end{tabular}

\begin{tabular}{c}
\hline Primary \\
\hline 127 \\
$45 \pm 1$ \\
$178 \pm 1$ \\
$90 \pm 2$ \\
$28.5 \pm 0.5$ \\
$2.11 \pm 0.02$ \\
$7.6(0.4-17.6)$ \\
$17.4(1.4-32.8)$ \\
$32 \pm 1$ \\
$12.0(10.6-12.7)$ \\
$22(11-38)$ \\
$481 \pm 6$ \\
$0.3(0.1-2.8)$ \\
$1.5(0.5-5.5)$ \\
$40 \pm 2$ \\
$16.0 \pm 0.5$
\end{tabular}

\begin{tabular}{c}
\hline Secondary \\
\hline 93 \\
$43 \pm 2$ \\
$176 \pm 1$ \\
$90 \pm 2$ \\
$28.8 \pm 0.5$ \\
$2.11 \pm 0.02$ \\
$0.1(0.1-0.6)$ \\
$0.5(0.2-2.6)^{\wedge}$ \\
$27 \pm 1^{\wedge}$
\end{tabular}

\begin{tabular}{c}
\hline $\mathbf{F 2 M}$ \\
\hline 101 \\
$29 \pm 1^{\#}$ \\
$165 \pm 1^{\#}$ \\
$75 \pm 2^{\#}$ \\
$27.3 \pm 0.6$ \\
$1.86 \pm 0.03^{\#}$ \\
$2.9(0.4-6.6)^{\#}$ \\
$3.8(1.2-6.1)^{\wedge}$ \\
$33.8 \pm 2^{\#}$
\end{tabular}

\begin{tabular}{c}
\hline $\boldsymbol{p}$ \\
\hline$<0.001$ \\
$<0.001$ \\
$<0.001$ \\
0.22 \\
$<0.001$ \\
$<0.001$ \\
$<0.001$ \\
0.015
\end{tabular}

Optimal inter-injection interval is determined from the average of the last three injections. Pre-titration serum LH and FSH are from the first blood samples at the entry to the study. Post-titration serum LH, FSH, SHBG, and testosterone are the last trough blood samples. Primary means primary (hypergonadotrophic) hypogonadism and secondary means secondary (hypogonadotrophic) hypogonadism, and F2M refers to female to male transgender. Data presented as mean \pm S.E.M. or median (interquartile range). \#Indicates significant difference from primary and secondary hypogonadism; *Indicates significant difference between primary and secondary hypogonadism; ^Indicates significant difference from primary hypogonadism.

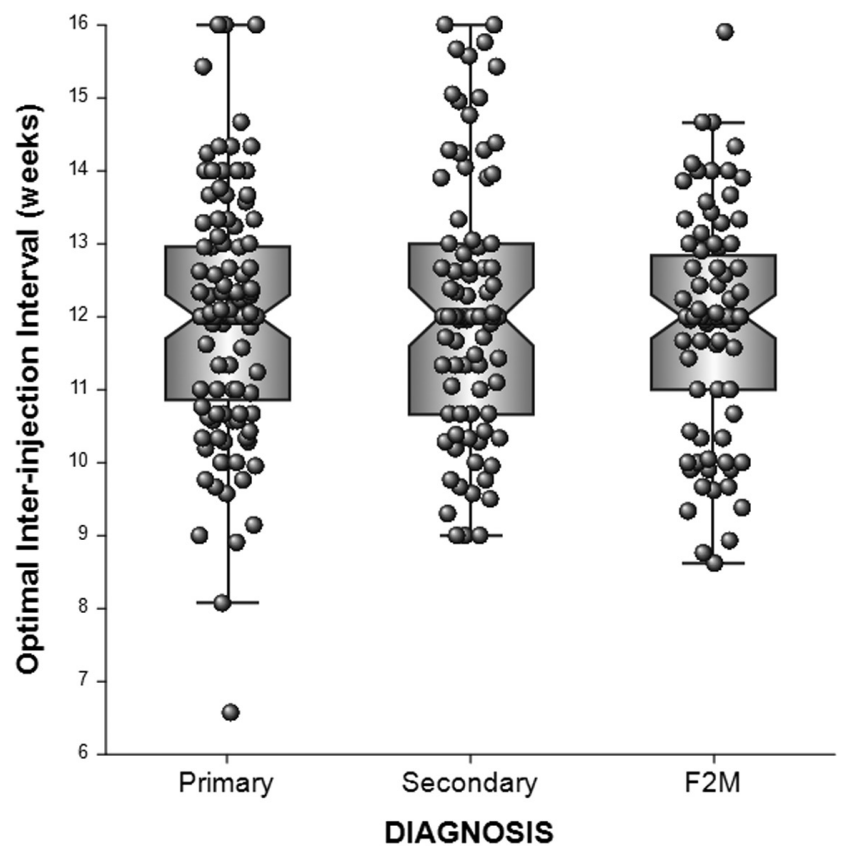

Figure 1

Box and dot plot of optimal inter-injection interval in weeks (y-axis) according to groups comprising primary hypogonadism, secondary hypogonadism, and female-to-male transgender (transmen). Each dot is the optimal inter-injection interval for one person. The superimposed box plot displays the quartiles as the notch, and box edges with whiskers representing an additional 1.5 times the interquartile interval. were significant predictors of inter-injection interval (Table 2). The magnitude of even the significant covariate effects was small with a 1 S.D. change in age and BSA (16.3 years and $0.27 \mathrm{~m}^{2}$, respectively) causing changes of 0.3 weeks in the optimal inter-injection interval. When restricting the linear mixed model analysis to the optimal inter-injection interval for each individual, the pattern was the same with significant effects of age $(P=0.001)$ and BSA $(P=0.001)$ but not serum FSH, LH, SHBG or diagnosis.

Shorter inter-injection intervals ( $<10$ weeks) were observed in $22 / 297$ (7\%) of patients who had a median of 24 injections and mean stable inter-injection intervals of $9.9 \pm 0.2$ weeks (median 9.9 weeks). Neither age nor BSA or other covariables were significant predictors of short inter-injection intervals. Longer intervals ( $\geq 14$ weeks) were observed 68/297 (23\%) of patients who had a median of 24 injections and mean stable inter-injection intervals of $13.9 \pm 0.2$ weeks (median 14.0 weeks). Longer intervals were positively correlated with age $(P=0.005)$ with a 1 S.D. increase in age predicting 0.5 weeks longer inter-injection interval but no other covariables were significant.

At the optimal regimen, serum LH was fully suppressed in men with primary hypogonadism to levels comparable with those of men with secondary hypogonadism. By contrast, in transmen, serum LH was minimally suppressed compared with pre-titration and significantly less suppressed than either group of hypogonadal men

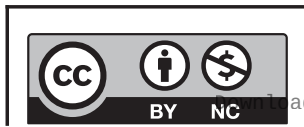

This work is licensed under a Creative Commons Attribution-NonCommercial 4.0 International License. ded from Bioscientifica.com at 04/26/2023 07:02:24AM via free access 

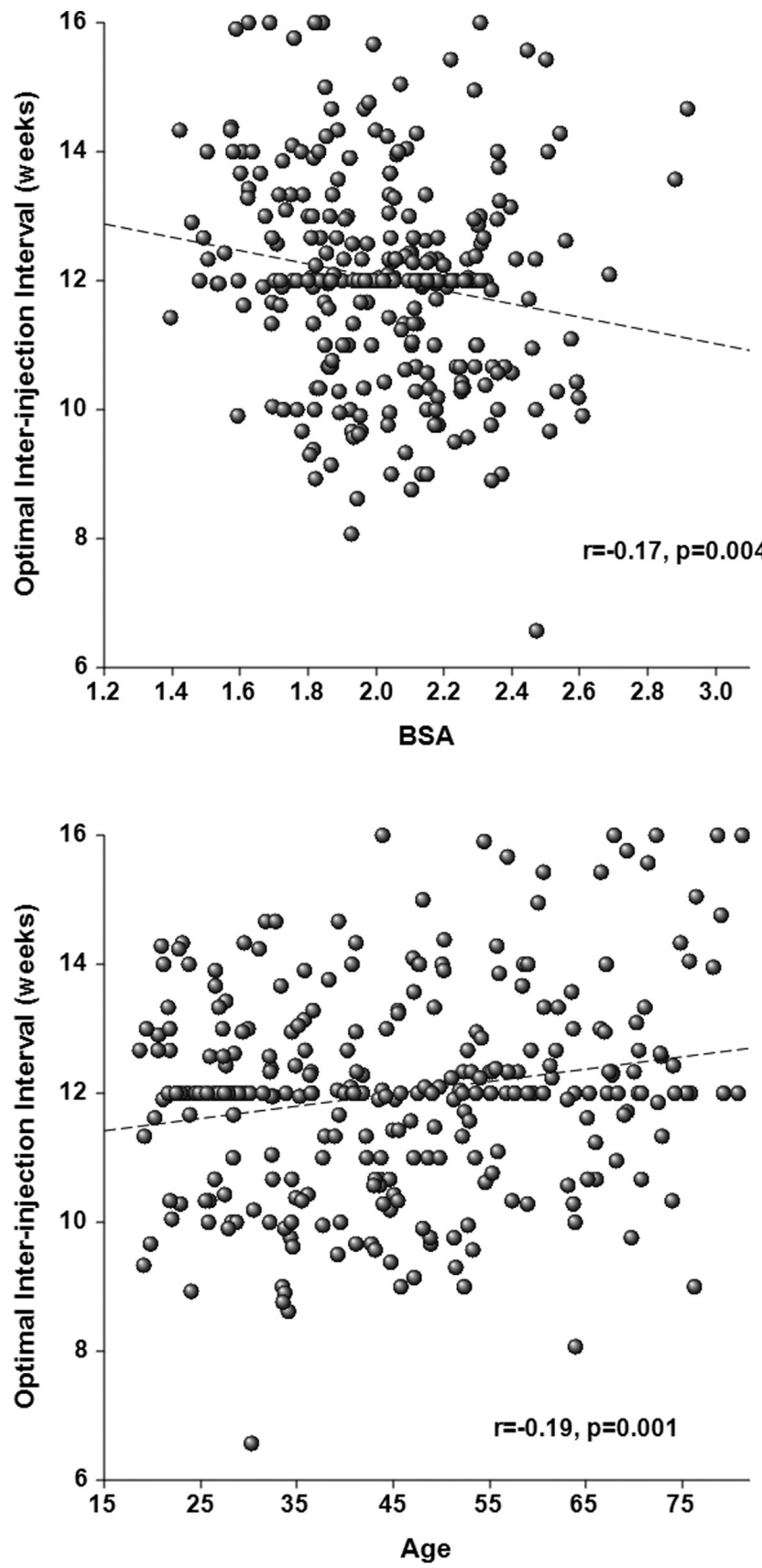

Figure 2

Regression analysis of optimal inter-injection interval according to BSA (top) and age (bottom). Each dot is the optimal inter-injection interval form of one individual with the dotted line representing the regression with the given correlation and $P$ value.

despite the higher dose per BSA. Serum FSH was markedly but not fully suppressed in men with primary compared with secondary hypogonadism, and in transmen, serum FSH was not suppressed.

Serum SHBG was significantly lower in men with secondary hypogonadism compared with those with
Table 2 Linear regression and linear mixed model analyses.

\begin{tabular}{|c|c|c|c|}
\hline & Coefficient & $\begin{array}{c}\text { Standardized } \\
\text { coefficient }\end{array}$ & $\boldsymbol{p}$ \\
\hline \multicolumn{4}{|l|}{$\begin{array}{l}\text { Linear } \\
\text { regression }\end{array}$} \\
\hline Age & 0.024 & 0.244 & $<0.001$ \\
\hline BSA & -1.39 & -0.228 & $<0.001$ \\
\hline Diagnosis & 0.043 & 0.022 & 0.74 \\
\hline \multicolumn{4}{|l|}{$\begin{array}{l}\text { Linear mixed } \\
\text { model }\end{array}$} \\
\hline Age & 0.017 & 5.67 & 0.005 \\
\hline BSA & -1.91 & 6.84 & 0.002 \\
\hline Diagnosis & 0.062 & 1.07 & 0.35 \\
\hline
\end{tabular}

primary hypogonadism and with transmen, but at the end of dose titration, there was no longer any significant difference between the three diagnostic groups (Table 1). Over the full course of treatment, serum SHBG was significantly increased with age $(0.25 \mathrm{nmol} / \mathrm{L}$ for every year of age, $P=0.003)$, decreased by BSA $\left(-1.5 \mathrm{nmol} / \mathrm{L}\right.$ for every $\left.0.1 \mathrm{~m}^{2}, P=0.002\right)$ and was lower in secondary hypogonadism compared with the other two diagnoses $(P=0.022)$.

Blood hemoglobin was increased beyond $180 \mathrm{~g} / \mathrm{L}$ in 8/497 (1.6\%) samples. Hemoglobin concentrations were

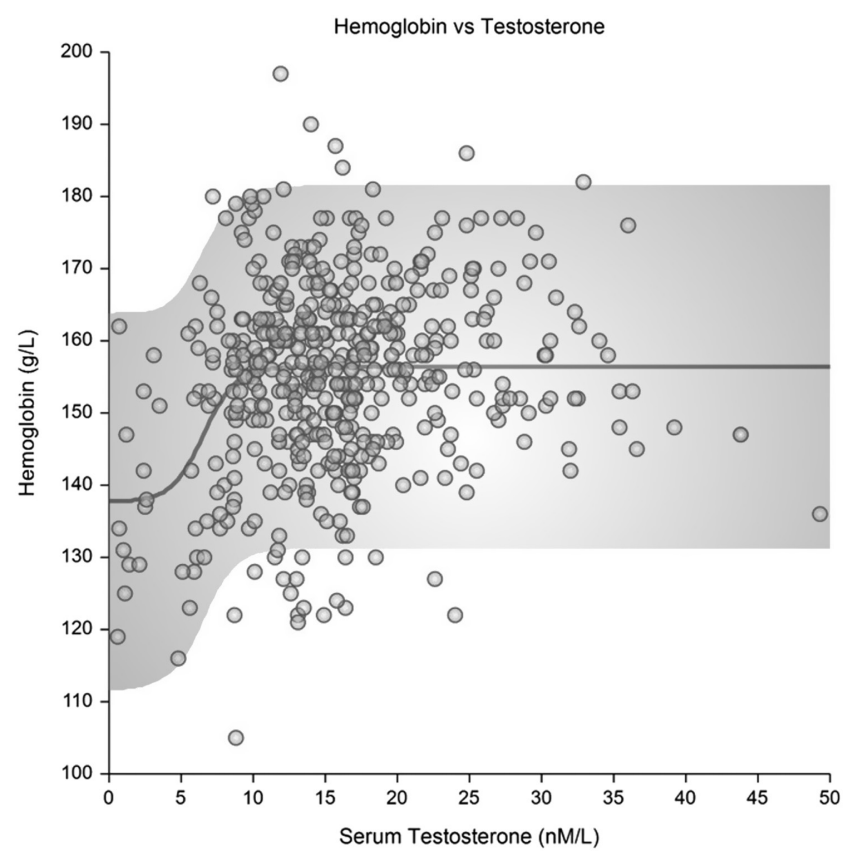

Figure 3

Scatter plot of blood hemoglobin (y-axis) plotted against trough serum testosterone ( $\mathrm{x}$-axis) with the best-fit 4 parameter sigmoidal curve in solid line and shaded region for the $95 \%$ prediction limits. The sigmoidal curve was defined as hemoglobin $=D+(A-D) /\left(1+(\text { testosterone } / C)^{\wedge} B\right)$ with $A$ (lower plateau $)=138 \pm 3$ and $D$ (upper plateau $)=156 \pm 0.7$ and shape factors $B$ (slope $)=-6.73 \pm 3.48$ and $C$ (midpoint $)=6.57 \pm 0.72$.

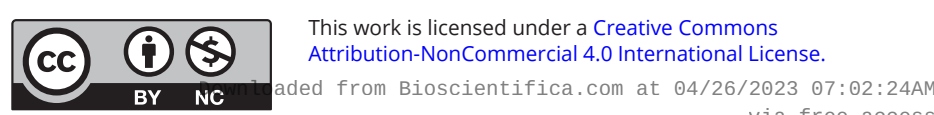


left-skewed $(\lambda=2.3)$ with the best non-linear regression model (according to highest $\mathrm{R}$ squared), a 4-parameter logistic regression analysis (Fig. 3) which was superior to linear, quadratic, piecewise, and Gompertz models. This showed a sigmoidal relationship between blood hemoglobin and trough serum testosterone rising from lower levels of both to an upper plateau in blood hemoglobin when serum testosterone reached about $10 \mathrm{nmol} / \mathrm{L}$ with no further increases in hemoglobin with higher serum testosterone concentrations. The median effective serum testosterone concentration was $6.5 \mathrm{nmol} / \mathrm{L}$. Blood hemoglobin did not differ significantly according to diagnosis (data not shown). Serum PSA was increased above the upper limit of the reference range $(4.0 \mathrm{ng} / \mathrm{mL})$ in $107 / 1204$ (8.9\%) of hypogonadal men and was significantly higher in men with primary $(1.9 \pm 1.9$ (S.D.); median $1.3(0.8-2.2, \mathrm{IQR}))$ rather than secondary hypogonadism $(1.4 \pm 1.5 ; 1.1(0.6-1.7))$.

\section{Discussion}

The present efficacy study observes that the approved duration of action of 12 weeks (after the loading dose) is vindicated based on individual dose titration consistent with previous observational clinical studies of regular clinical practice. Nevertheless, individual optimizing of injectable TU leads to a minority of both longer (23\%) and shorter (7\%) inter-injection intervals. This reflects the variability of the pharmacokinetic profile between individuals and even between injections, which are mostly masked by the time window design of conventional pharmacokinetic studies, and much greater variability is revealed by population pharmacokinetic analysis using sampling at times unconstrained by fixed time windows (22). An important observation is that the pharmacology of injectable TU does not differ materially between hypogonadal and transgender men.

The present study features individual dose titration based on the durability of androgen effects such as surveillance for recurrence of the patient's own characteristic lead symptoms together with the trough serum testosterone and, in primary hypogonadism, suppression of serum LH and FSH. This approach is based on the consistency of each man's lead symptom of androgen deficiency due to pathological hypogonadism with characteristic and reproducible serum testosterone threshold (18). In addition, this is supported by the objective criteria of trough serum testosterone in the low-normal eugonadal reference range and, for men with primary hypogonadism, suppression of serum LH and FSH. An optimal regimen would expect to feature serum LH suppressed to low or undetectable serum LH levels and serum FSH also markedly suppressed although less than for serum LH. This approach to individual titration is more practical and effective than titration based on symptoms and blood testosterone (+ serum LH and FSH) at the midpoint of the injection interval which requires an extra visit that is difficult to schedule accurately and at times, when serum testosterone is most highly variable (22). The present findings demonstrate that after individual dose titration, serum LH and FSH are markedly less suppressible in transmen compared with men with primary or secondary hypogonadism despite a higher dose in microgram per square meter. Most of the transmen had intact ovaries so the additional impact of ovariectomy could not be assessed.

The duration of action of injectable TU based on the optimized stable inter-injection interval is significantly, but weakly, influenced by age and body size. The modeling indicates that BSA, as a measure of overall body size, is the most effective explanatory variable representing body size or physique, and in these analyses, BSA represents a measure of overall body size correlated with total body water or extracellular fluid through which testosterone is distributed. This finding is consistent with previous pharmacokinetic findings that body size determines serum testosterone after two doses in healthy eugonadal men (23) or three doses in hypogonadal men (24). Beyond the limited dosing of a fixed injection regimen, the present study evaluated optimized steady-state serum testosterone after a median of 14 injections. Age was a consistent but weak significant predictor of inter-injection interval overall and for longer but not shorter intervals. Nevertheless, the covariate effects of age and BSA are of such modest magnitude $(<0.5$ weeks) that they do not attain significance for regular clinical practice. For example, despite the F2M patients being smaller and lighter (due to their underlying female biological origins) compared with men with hypogonadism, there was no difference in optimized interinjection interval according to diagnosis. This finding is consistent with previous pharmacokinetic findings of injectable TU showing serum and urine steroid profiles were similar in hypogonadal and transmen (16). Overall, these covariates reflecting age, body size, and hormonal responses to testosterone treatment exert only minimal effect of optimal inter-injection interval so that beyond optimizing treatment regimens they do not need additional clinical consideration. One practical implication of these findings is for regulating testosterone replacement therapy 
for elite athletes with organic male hypogonadism (25) or female-to-male transgenders (26) where the approved dosage must be limited to physiological replacement to avoid the unfair ergogenic advantage of excessive dosage.

The present study's findings on blood hemoglobin and serum PSA provide additional evidence for the efficacy and safety of injectable TU. This study focused on hemoglobin as a more robust measure than hematocrit $(27,28)$. Only a small minority (1.6\%) of samples displayed erythrocytosis (hemoglobin $>180 \mathrm{~g} / \mathrm{L}$ ) and a larger butstill small proportion (8.9\%) displayed high serum PSA concentrations (> $4.0 \mathrm{ng} / \mathrm{mL}$ ), both of which may lead to reducing testosterone dosage by wider inter-injection spacing intervals. Overall, hemoglobin displayed a sigmoidal pattern of increase with higher serum testosterone concentrations in the low range of serum testosterone. After starting both at low concentrations, hemoglobin then increases to reach a plateau at characteristic eugonadal male hemoglobin concentrations when serum testosterone reached about $10 \mathrm{nmol} / \mathrm{L}$. This is consistent with our previous findings that erythrocytosis occurs in a small number of individuals in the testosterone trials (29) as well as hypogonadal men treated with testosterone (30) or healthy men treated with dihydrotestosterone (31). In concert, these findings suggest that testosterone-induced erythrocytosis is not simply a dose-response in increasing testosterone exposure but rather an idiosyncratic response to androgen exposure in a small minority of patients, presumably with underlying genetic susceptibility.

Other variables that might influence inter-injection interval but not measured in this study include functional genetic variants of androgen metabolism. These include the androgen receptor (AR) CAG triplet repeat polymorphism (32) and the uridine diphospho-glucuronosyl transferase 2B17 (UGT2B17) polymorphism in testosterone glucuronidation rendering the steroid more hydrophilic for renal excretion (33). The UGT2B17 polymorphism primarily influences testosterone glucuronide excretion (34) but not circulating testosterone concentrations (16, 35) so has minor or no impact on androgen action (36) or tumor susceptibility (37). Similarly, the CAG repeat polymorphism in the androgen receptor has some influence on androgen sensitivity with polymorphism length inversely proportional to androgen sensitivity in vitro (38), experimentally in vivo (39), and inferred from most observational clinical studies (40) and with a small, variable effect reported in some $(41,42)$ but not all (43) studies of testosterone pharmacodynamics. While it cannot be excluded that the androgen receptor CAG triplet repeat polymorphism may influence the pharmacodynamics of injectable TU, neither genetic polymorphism is likely to be of sufficient clinical significance for stabilizing injectable $\mathrm{TU}$ treatment to make genetic testing cost-effective.

The strengths of the present study are its basis on its large consecutive series of serial injections confirming that the individually optimized injectable TU regimen has a usual duration of action of 12 weeks, consistent with its marketing approvals. The duration of action was essentially the same in hypogonadal and transmen thereby allowing consistent use of injectable TU in those groups without systematic dose adjustment beyond individual dose titration. However individual dose titration to achieve optimal testosterone replacement therapy in men with pathological hypogonadism can lead to significantly shorter or longer intervals in about $30 \%$ of patients. However, the present findings do not identify any practical workaround to bypass the need for individual dose titration based on lead symptom relief and runoff together with trough serum testosterone. A limitation of the present study is that it relied on testosterone immunoassays rather than liquid chromatography-mass spectrometry measurements which were not available routinely in our clinic. This also dictated that we did not have reliable serum estradiol or dihydrotestosterone measurements. Nevertheless, the same testosterone immunoassay which was subject to an external quality control program was used consistently. Another limitation is that we were not able to analyze hemoglobin/hematocrit data as it was not measured in the same depth as testosterone, although erythrocytosis is an infrequent but regular reason for having to extend the inter-injection interval. However, we have previously shown that trough serum testosterone (30) as well as higher baseline hemoglobin (31) is predictors of androgeninduced erythrocytosis. Finally, the present findings in men with pathological hypogonadism may not generalize to injectable TU treatment for healthy eugonadal men or those with a functional or age-related reduction in serum testosterone in whom endogenous testosterone production is not impaired by pathological reproductive system disorders.

\section{Declaration of interest}

The authors declare that there is no conflict of interest that could be perceived as prejudicing the impartiality of the research reported.

\section{Funding}

This study was partly supported by the 2019 Endocrine Society of Australia Ferring Innovation and Clinical Excellence Award in Male Hypogonadism.

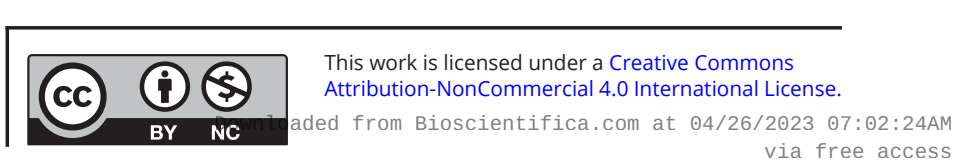


The testosterone product manufacturer provided no funding or other input into this work.

\section{References}

1 Handelsman DJ. Androgen physiology, pharmacology and abuse. In Endocrinology, 7th ed., pp. 2368-2370. Eds LJ DeGroot \& JL Jameson. Philadelphia: Elsevier Saunders, 2015.

2 Junkman K. Long-acting steroids in reproduction. Recent Progress in Hormone Research 195713 380-419.

3 Kalicharan RW, Oussoren C, Schot P, de Rijk E \& Vromans H. The contribution of the in-vivo fate of an oil depot to drug absorption. International Journal of Pharmaceutics 2017528 595-601. (https://doi. org/10.1016/j.ijpharm.2017.06.055)

4 Swerdloff RS, Wang C, White WB, Kaminetsky J, Gittelman MC, Longstreth JA, Dudley RE \& Danoff TM. A new oral testosterone undecanoate formulation restores testosterone to normal concentrations in hypogonadal men. Journal of Clinical Endocrinology and Metabolism 2020105 2515-2531. (https://doi.org/10.1210/clinem/ dgaa238)

5 Zhang GY, Gu YQ, Wang XH, Cui YG \& Bremner WJ. A pharmacokinetic study of injectable testosterone undecanoate in hypogonadal men. Journal of Andrology 199819 761-768.

6 Handelsman DJ. Androgen physiology, pharmacology, use and misuse. In Endotext. Eds KR Feingold, B Anawalt, A Boyce, et al. South Dartmouth (MA), 2020.

7 Jacobeit JW, Gooren LJ \& Schulte HM. Long-acting intramuscular testosterone undecanoate for treatment of female-to-male transgender individuals. Journal of Sexual Medicine 20074 1479-1484. (https://doi. org/10.1111/j.1743-6109.2007.00556.x)

8 Handelsman DJ, Conway AJ \& Boylan LM. Pharmacokinetics and pharmacodynamics of testosterone pellets in man. Journal of Clinical Endocrinology and Metabolism 199071 216-222. (https://doi. org/10.1210/jcem-71-1-216)

9 Kelleher S, Howe C, Conway AJ \& Handelsman DJ. Testosterone release rate and duration of action of testosterone pellet implants. Clinical Endocrinology 200460 420-428. (https://doi.org/10.1111/j.13652265.2004.01994.x)

10 Minnemann T, Schubert M, Freude S, Hubler D, Gouni-Berthold I, Schumann C, Christoph A, Oettel M, Ernst M, Mellinger U, et al. Comparison of a new long-acting testosterone undecanoate formulation vs testosterone enanthate for intramuscular androgen therapy in male hypogonadism. Journal of Endocrinological Investigation 200831 718-723. (https://doi.org/10.1007/BF03346421)

11 Jockenhovel F, Minnemann T, Schubert M, Freude S, Hubler D, Schumann C, Christoph A \& Ernst M. Comparison of long-acting testosterone undecanoate formulation versus testosterone enanthate on sexual function and mood in hypogonadal men. European Journal of Endocrinology 2009160 815-819. (https://doi.org/10.1530/EJE-08-0830)

12 Wierckx K, Van Caenegem E, Schreiner T, Haraldsen I, Fisher AD, Toye K, Kaufman JM \& T'Sjoen G. Cross-sex hormone therapy in trans persons is safe and effective at short-time follow-up: results from the European network for the investigation of gender incongruence. Journal of Sexual Medicine 201411 1999-2011. (https://doi.org/10.1111/ jsm.12571)

13 Sartorius G, Fennell C, Spasevska S, Turner L, Conway AJ \& Handelsman DJ. Factors influencing time course of pain after depot oil intramuscular injection of testosterone undecanoate. Asian Journal of Andrology 201012 227-233. (https://doi.org/10.1038/aja.2010.1)

14 Middleton T, Turner L, Fennell C, Savkovic S, Jayadev V, Conway AJ $\&$ Handelsman DJ. Complications of injectable testosterone undecanoate in routine clinical practice. European Journal of Endocrinology 2015172 511-517. (https://doi.org/10.1530/EJE-14-0891)
15 Defreyne J, Vantomme B, Van Caenegem E, Wierckx K, De Blok CJM, Klaver M, Nota NM, Van Dijk D, Wiepjes CM, Den Heijer M, et al. Prospective evaluation of hematocrit in gender-affirming hormone treatment: results from European network for the investigation of gender incongruence. Andrology 20186 446-454. (https://doi. org/10.1111/andr.12485)

16 Savkovic S, Lim S, Jayadev V, Conway A, Turner L, Curtis D, Goebel C \& Handelsman DJ. Urine and serum sex steroid profile in testosteronetreated transgender and hypogonadal and healthy control men. Journal of Clinical Endocrinology and Metabolism 2018103 2277-2283. (https://doi.org/10.1210/jc.2018-00054)

17 Feinstein AR. Clinical biostatistics. LVII. A glossary of neologisms in quantitative clinical science. Clinical Pharmacology and Therapeutics 198130 564-577. (https://doi.org/10.1038/clpt.1981.204)

18 Kelleher S, Conway AJ \& Handelsman DJ. Blood testosterone threshold for androgen deficiency symptoms. Journal of Clinical Endocrinology and Metabolism 200489 3813-3817. (https://doi.org/10.1210/jc.2004-0143)

19 Handelsman DJ. Androgen use, misuse and abuse. In Endocrinology of the Testis and Male Reproduction, pp. 1251-1285. Eds M Simoni \& IT Huhtaniemi. Springer International, 2017.

20 Redlarski G, Palkowski A \& Krawczuk M. Body surface area formulae: an alarming ambiguity. Scientific Reports 20166 27966. (https://doi. org/10.1038/srep27966)

21 Handelsman DJ. Optimal power transformations for analysis of sperm concentration and other semen variables. Journal of Andrology 200223 629-634

22 Turner L, Ly LP, Desai R, Singh GKS, Handelsman TD, Savkovic S, Fennell C, Jayadev V, Conway A \& Handelsman DJ. Pharmacokinetics and acceptability of subcutaneous injection of testosterone undecanoate. Journal of the Endocrine Society 20193 1531-1540. (https://doi.org/10.1210/js.2019-00134)

23 Kornmann B, Nieschlag E, Zitzmann M, Gromoll J, Simoni M \& von Eckardstein S. Body fat content and testosterone pharmacokinetics determine gonadotropin suppression after intramuscular injections of testosterone preparations in normal men. Journal of Andrology $20093 \mathbf{3 0}$ 602-613. (https://doi.org/10.2164/jandrol.108.006296)

24 Moisey R, Swinburne J \& Orme S. Serum testosterone and bioavailable testosterone correlate with age and body size in hypogonadal men treated with testosterone undecanoate (1000 mg IM-Nebido) Clinical Endocrinology 200869 642-647. (https://doi.org/10.1111/j.13652265.2008.03251.x)

25 WADA. Medical Information to Support the Decisions of TUECs - Androgen Deficiency-Male Hypogonadism (Version 6.2). Montreal: WADA, 2019.

26 WADA. Medical Information to Support the Decisions of TUECs - Female to Male Transsexual Athletes (Version 1.1). Montreal: WADA, 2019.

27 Cohle SD, Saleem A \& Makkaoui DE. Effects of storage of blood on stability of hematologic parameters. American Journal of Clinical Pathology 198176 67-69. (https://doi.org/10.1093/ajcp/76.1.67)

28 Pinter E, Laszlo K, Schuszler I \& Konderak J. The stability of quantitative blood count parameters using the Advia 2120i hematology analyzer. Practical Laboratory Medicine 20164 16-21. (https://doi.org/10.1016/j.plabm.2015.12.001)

29 Roy CN, Snyder PJ, Stephens-Shields AJ, Artz AS, Bhasin S, Cohen HJ, Farrar JT, Gill TM, Zeldow B, Cella D, et al. Association of testosterone levels with anemia in older men: a controlled clinical trial. JAMA Internal Medicine 2017177 480-490. (https://doi.org/10.1001/ jamainternmed.2016.9540)

30 Ip FF, di Pierro I, Brown R, Cunningham I, Handelsman DJ \& Liu PY. Trough serum testosterone predicts the development of polycythemia in hypogonadal men treated for up to 21 years with subcutaneous testosterone pellets. European Journal of Endocrinology 2010162 385-390. (https://doi.org/10.1530/EJE-09-0717)

31 Idan A, Griffiths KA, Harwood DT, Seibel MJ, Turner L, Conway AJ \& Handelsman DJ. Long-term effects of dihydrotestosterone treatment on prostate growth in healthy, middle-aged men without prostate https://ec.bioscientifica.com https://doi.org/10.1530/EC-21-0109 (c) 2021 The authors Published by Bioscientifica Ltd

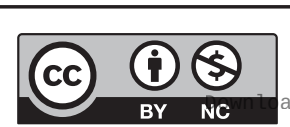

This work is licensed under a Creative Commons Attribution-NonCommercial 4.0 International License. ded from Bioscientifica.com at 04/26/2023 07:02:24AM 
disease: a randomized, placebo-controlled trial. Annals of Internal Medicine 2010153 621-632. (https://doi.org/10.7326/0003-4819-15310-201011160-00004)

32 Rajender S, Singh L \& Thangaraj K. Phenotypic heterogeneity of mutations in androgen receptor gene. Asian Journal of Andrology $2007 \mathbf{9}$ 147-179. (https://doi.org/10.1111/j.1745-7262.2007.00250.x)

33 Xue Y, Sun D, Daly A, Yang F, Zhou X, Zhao M, Huang N, Zerjal T, Lee C, Carter NP, et al. Adaptive evolution of UGT2B17 copy-number variation. American Journal of Human Genetics 200883 337-346. (https://doi.org/10.1016/j.ajhg.2008.08.004)

34 Jakobsson J, Ekstrom L, Inotsume N, Garle M, Lorentzon M, Ohlsson C, Roh HK, Carlstrom K \& Rane A. Large differences in testosterone excretion in Korean and Swedish men are strongly associated with a UDP-glucuronosyl transferase 2B17 polymorphism. Journal of Clinical Endocrinology and Metabolism 200691 687-693. (https://doi.org/10.1210/jc.2005-1643)

35 Ponzetto F, Mehl F, Boccard J, Baume N, Rudaz S, Saugy M \& Nicoli R. Longitudinal monitoring of endogenous steroids in human serum by UHPLC-MS/MS as a tool to detect testosterone abuse in sports. Analytical and Bioanalytical Chemistry 2016408 705-719. (https://doi. org/10.1007/s00216-015-9185-1)

36 Mouritsen A, Busch AS, Aksglaede L, Rajpert-De Meyts E \& Juul A. Deletion in the uridine diphosphate glucuronyltransferase 2B17 gene is associated with delayed pubarche in healthy boys. Endocrine Connections 20187 460-465. (https://doi.org/10.1530/EC-18-0080)

37 Deng X, Cheng Y, Yang X, Li S, Zhao R, Liu K, Liu J, Cao Q, Qin C, Shao $\mathrm{P}$, et al. Meta-analysis reveals a lack of association between UGT2B17 deletion polymorphism and tumor susceptibility. PLOS ONE 20149 e96812. (https://doi.org/10.1371/journal.pone.0096812)
38 Beilin J, Ball EM, Favaloro JM \& Zajac JD. Effect of the androgen receptor CAG repeat polymorphism on transcriptional activity: specificity in prostate and non-prostate cell lines. Journal of Molecular Endocrinology 200025 85-96. (https://doi.org/10.1677/jme.0.0250085)

39 Simanainen U, Brogley M, Gao YR, Jimenez M, Harwood DT, Handelsman DJ \& Robins DM. Length of the human androgen receptor glutamine tract determines androgen sensitivity in vivo. Molecular and Cellular Endocrinology 2011342 81-86. (https://doi. org/10.1016/j.mce.2011.05.011)

40 Eendebak RJ, Huhtaniemi IT, Pye SR, Ahern T, O'Neill TW, Bartfai G, Casanueva FF, Maggi M, Forti G, Alston RD, et al. The androgen receptor gene CAG repeat in relation to 4-year changes in androgensensitive endpoints in community-dwelling older European men. European Journal of Endocrinology 2016175 583-593.

41 Tirabassi G, delli Muti N, Gioia A, Biagioli A, Lenzi A \& Balercia G. Effects of testosterone replacement therapy on bone metabolism in male post-surgical hypogonadotropic hypogonadism: focus on the role of androgen receptor CAG polymorphism. Journal of Endocrinological Investigation 201437 393-400.

42 Zitzmann M, Depenbusch M, Gromoll J \& Nieschlag E. Prostate volume and growth in testosterone-substituted hypogonadal men are dependent on the CAG repeat polymorphism of the androgen receptor gene: a longitudinal pharmacogenetic study. Journal of Clinical Endocrinology and Metabolism 200388 2049-2054.

43 Giagulli VA, Triggiani V, Carbone MD, Corona G, Tafaro E, Licchelli B \& Guastamacchia E. The role of long-acting parenteral testosterone undecanoate compound in the induction of secondary sexual characteristics in males with hypogonadotropic hypogonadism. Journal of Sexual Medicine 20118 3471-3478.

Received in final form 31 May 2021

Accepted 16 June 2021

Accepted Manuscript published online 17 June 2021
This work is licensed under a Creative Commons Attribution-NonCommercial 4.0 International License. ded from Bioscientifica.com at 04/26/2023 07:02:24AM 